\title{
Ausgewählte Aspekte zum Thema Betriebserlaubnis und Zertifizierung elektrischer Anlagen für den Netzanschluss
}

R. Schürhuber OVE

Der Netzanschluss von Erzeugungsanlagen wird in Österreich über die TOR-Bedingungen (Technische und organisatorische Regeln für Betreiber und Benutzer von Netzen) geregelt. Mit April 2019 wird die EU-Verordnung 2016/631 anwendbar, welche den Netzanschluss EU-weit regelt und somit eine Anpassung der nationalen
Richtlinien bedingt. In diesem Tutorial werden die dadurch entstehenden Rahmenbedingungen beschrieben, es wird auf einige neu zu erfüllende technische Bedingungen eingegangen sowie der aktuelle Stand des Betriebserlaubnisverfahrens für Erzeugungsanlagen erläutert. 